\title{
Proliferation of Recombinant PVY Strains in Two Potato-Producing Regions of Canada, and Symptom Expression in 30 Important Potato Varieties with Different PVY Strains
}

\author{
Tyler D. B. MacKenzie, ${ }^{1}$ Xianzhou Nie, ${ }^{2}$ Vikram Bisht, ${ }^{3}$ and Mathuresh Singh ${ }^{1, \dagger}$ \\ ${ }^{1}$ Agricultural Certification Services Inc., Fredericton, New Brunswick, E3B 8B7, Canada \\ ${ }^{2}$ Fredericton Research and Development Centre, Agriculture and Agri-Food Canada, Fredericton, \\ New Brunswick, E3B 4Z7, Canada \\ ${ }^{3}$ Manitoba Agriculture, Carman, Manitoba R0G 0J0, Canada
}

\begin{abstract}
Potato virus $Y$ (PVY) exists as several strains with distinct symptomology and tuber yield effects in different potato varieties. Recently, new recombinant strains have proliferated and dominated local populations around the world. In this study, $\mathrm{PVY}^{\mathrm{O}}, \mathrm{PVY}^{\mathrm{N}: \mathrm{O}}, \mathrm{PVY}^{\mathrm{N}-\mathrm{Wi}}$, and PVY ${ }^{\mathrm{NTN}}$ strains were tracked across Canada from 2014 to 2017, showing rapid evolution of populations away from the traditionally dominant $\mathrm{PVY}$ to recombinants PVY ${ }^{\mathrm{N}-\mathrm{Wi}}$ (western Canada) and PVY ${ }^{\mathrm{NTN}}$ (eastern Canada). Simultaneously, 30 potato varieties were inoculated with $\mathrm{PVY}^{\mathrm{O}}$, $\mathrm{PVY}^{\mathrm{N}: \mathrm{O}}$, and PVY ${ }^{\mathrm{NTN}}$ in controlled greenhouse experiments. Foliar

secondary infection, symptom expression and yield reduction were most severe with $\mathrm{PVY}^{\mathrm{O}}$, followed by $\mathrm{PVY}^{\mathrm{N}: \mathrm{O}}$ and $\mathrm{PVY}^{\mathrm{NTN}}$. Strong mosaic symptoms were most commonly expressed with $\mathrm{PVY} \mathrm{O}^{\mathrm{O}}$ infection, and only seen with $\mathrm{PVY}^{\mathrm{N}: \mathrm{O}}$ or PVY $\mathrm{PTN}^{\mathrm{NT}}$ in 15 and 3 varieties, respectively. Across variety-strain combinations, yield reduction was correlated with symptom severity, most strongly in $\mathrm{PVY}^{\mathrm{O}}$-infected plants (e.g., $\mathrm{AC}$ Chaleur, Beljade, Envol, Norland, and Pacific Russet), and four varieties exhibited tuber necrotic ringspot disease with PVY ${ }^{\text {NTN }}$ (AC Chaleur, Envol, Pacific Russet, and Yukon Gold).
\end{abstract} symptoms of primary (mechanical inoculation mimicking aphid infection) and secondary (tuber seedborne) infection were cataloged, and tuber yield measured. On average, and generally similar in primary and
Keywords: crop protection, populations, potato varieties, PVY strains, symptom expression
Potato is one of the most important food crops around the world, and its production is subject to considerable pressure by viral diseases. Potato virus Y (PVY; genus Potyvirus, family Potyviridae) is the most economically damaging viral disease of potato, causing substantial yield reduction and, in some cases, tuber necrosis in infected plants (Karasev and Gray 2013). PVY was first recognized as the causative agent for a debilitating mosaic disease in potato in the early 20th century, and was differentiated into three major strains $\left(\mathrm{PVY}^{\mathrm{O}}, \mathrm{PVY}^{\mathrm{N}}\right.$, and $\mathrm{PVY}^{\mathrm{C}}$ ) based upon symptom expression in potato and tobacco in the 1940s (Cockerham 1943). Additional strains were discovered later, including several recombinant strains mostly developed from $P V Y^{\mathrm{O}}$ and $\mathrm{PVY}^{\mathrm{N}}$ parental lineages (e.g., PVY ${ }^{\mathrm{NTN}}$ in 1978 and $\mathrm{PVY}^{\mathrm{N}-\mathrm{Wi}}$ and PVY ${ }^{\mathrm{N}: \mathrm{O}}$ in 1984) (Blanchard et al. 2008; Singh et al. 2008). Extensive phylogenetic studies and molecular clock analysis suggest that these recombinant strains evolved very recently (1970s to 1990s) (Visser et al. 2012).

Rapid evolution of PVY over the past century, especially by viral recombination, has complicated strain definitions based upon host symptom expression and serology (Blanchard et al. 2008, Nie et al. 2012). Recently, whole-genome sequencing of many diverse PVY isolates, currently numbering approximately 400 published genomes (Green et al. 2017), has led to reclassification of PVY strains based on RNA sequence and legacy of genetic recombination events.

${ }^{\dagger}$ Corresponding author: M. Singh; msingh@ @otatoesnb.com

Funding: This work was generously funded by the Canadian Agri-Science Cluster for Horticulture 2, in partnership with Agriculture and Agri-Food Canada's AgriInnovation Program, the Canadian Horticultural Council-Growing Forward 2 (Activity \#13, Potato 12; AIP-CL-18), and industry contributors.

The author(s) declare no conflict of interest.

Accepted for publication 7 March 2019.

(c) 2019 The American Phytopathological Society
In many potato-growing regions worldwide, multiple strains are found simultaneously within regions, fields, or even individual plants; in most areas, however, the predominant strains have been changing recently (Bai et al. 2019; Funke et al. 2017; Karasev and Gray 2013), with the traditionally dominant $P V Y^{\mathrm{O}}$ being rapidly replaced by recombinant strains $\mathrm{PVY}^{\mathrm{NTN}}, \mathrm{PVY}^{\mathrm{N}: \mathrm{O}}$, and $\mathrm{PVY}^{\mathrm{N}-\mathrm{Wi}}$ (Blanchard et al. 2008; Chikh Ali et al. 2010; Davie et al. 2017; Djilani-Khouadja et al. 2010; Gray et al. 2010; Karasev and Gray 2013; MacKenzie et al. 2018; Schubert et al. 2007). Although the mechanisms causing proliferation of these recombinant strains are unclear, they may include enhanced plant-to-plant transmission, aided by selective resistance against $\mathrm{PVY} \mathrm{P}^{\mathrm{O}}$ in some potato varieties (Funke et al. 2017; MacKenzie et al. 2018), unseen multiplication of recombinants in the field in asymptomatic varieties such as Russet Norkotah and Shepody (Karasev and Gray 2013) or other selective pressures increasing loss of $\mathrm{PVY}^{\mathrm{O}}$ plants from the field, or decreasing transmission likelihood or yield of $\mathrm{PVY}^{\mathrm{O}}$-infected tubers (Lindner et al. 2015).

Although the taxonomic diversity of PVY strains is now primarily determined genetically and not by serology or symptom expression (Green et al. 2017; Kehoe and Jones 2015), these newer recombinant strains can nevertheless exhibit distinct and varietyspecific symptoms in potato. Traditionally, PVY infection has been associated with a characteristic patchy discoloration of the leaves which gave rise to the "mosaic disease" terminology. Several other common symptoms include leaf deformation (stunting, crinkling, twisting, or rolling), chlorosis, localized necrotic spotting, leaf drop, plant stunting, and early senescence. Not all potato varieties display all these symptoms, however, nor do all strains of PVY elicit them equally within a variety. Also, other environmental stressors (Draper et al. 2002) or coinfection with other viruses such as Potato virus X (PVX) (Nie and Singh 2013) can alter symptom presentation or severity. Certain varieties are genetically predisposed to localized or systemic hypersensitive resistance to combat infection but the responsible resistance genes ( $N$ genes, including $N y, N c$, and $N z$ ) are often specific to particular PVY strains (Jones and Vincent 2018; Nie et al. 2015). 
This study assessed the recent and evolving populations of PVY strains in eastern and western Canada, and systematically cataloged symptom responses in a wide range of commercially important potato varieties following infection with $\mathrm{PVY}^{\mathrm{O}}, \mathrm{PVY}^{\mathrm{N}: \mathrm{O}}$, and $\mathrm{PVY}{ }^{\mathrm{NTN}}$. Several recent reviews discuss potential threats of recombinant strains of PVY (Karasev and Gray 2013; Nie et al. 2012). In addition to the more rapid spread of these strains, important among these threats are the strain-specific symptoms elicited in the host potato plant (Blanchard et al. 2008). Common questions are (i) do infections by recombinant strains usually result in more cryptic foliar symptoms in common potato varieties, allowing evasion of control practices such as roguing, and (ii) how widespread is the expression of potato tuber necrotic ringspot disease (PTNRD) (Beczner et al. 1984) with infection by the now more common PVY ${ }^{\mathrm{NTN}}$ ? Concurrently, selected potato varieties were grown and inoculated with different strains of PVY in the greenhouse, and replicate plants were observed for foliar and tuber symptoms in both primary (leaf inoculation) and secondary (seed tuberborne) infection. Across 30 tested varieties, generalities and differences in symptoms and tuber yield caused by infection with the different PVY strains were assessed, the predictability of tuber yield reduction based on symptom severity was quantified, and the frequency of varieties showing the most concerning symptom of tuber necrosis was determined.

\section{Materials and Methods}

PVY survey sample collection and PVY strain typing. Potato leaf and tuber samples were collected for PVY screening and strain typing from potato-producing provinces in western (predominantly British Columbia and Manitoba) and eastern (predominantly New Brunswick) Canada from 2014 to 2017. Sample collections of symptomatic and nonsymptomatic leaves during the growing season were made by provincial government staff or partner organizations in these provinces. Tubers were randomly sampled from different seed lots by authorized personnel and submitted for mandatory postharvest virus testing; these tubers were selected regardless of any symptoms present, though they were largely asymptomatic. A summary of PVY samples, number of field lots, and varieties is shown in Table 1.

PVY was detected using the double-antibody sandwich enzymelinked immunosorbent assay (ELISA) method (Singh et al. 2003) from fresh leaves, or tubers sprouted after dormancy was broken with rindite (Gugerli and Gehriger 1980). RNA extraction on leaf and tuber sap samples testing PVY positive with ELISA was done with TriReagent (Molecular Research Center, Inc., Cincinnati, OH, U.S.A.) following the manufacturer's instructions. Complementary DNA (cDNA) was synthesized (Nie and Singh 2001); then, strainspecific multiplex polymerase chain reaction (PCR) was performed following Lorenzen et al. (2006) after products were resolved by electrophoresis through a $2.5 \%$ agarose gel in $0.5 \times$ Tris-borateEDTA. In total, 928 PVY-positive samples (191 and 737 from western and eastern Canada, respectively) were strain typed with the Lorenzen et al. (2006) protocol. Details on numbers of samples, field lots, and varieties represented for each region and year are given in Table 1. Subsets of 58 and 95 PVY-positive samples from western and eastern Canada, respectively, were also tested with the Chikh Ali et al. (2010) method to confirm results identified by the Lorenzen protocol to further confirm the PVY strain typing.

Table 1. Total numbers of Potato virus $Y$ (PVY) samples, field lots, and potato varieties sampled from western and eastern Canada for calculating PVY strain proportions

\begin{tabular}{cccccccc}
\hline & \multicolumn{3}{c}{ Western Canada } & & \multicolumn{3}{c}{ Eastern Canada } \\
\cline { 2 - 3 } Year & $\begin{array}{c}\text { PVY-positive } \\
\text { samples }\end{array}$ & Lots & Varieties $^{\mathbf{a}}$ & & $\begin{array}{c}\text { PVY-positive } \\
\text { samples }\end{array}$ & Lots & Varieties $^{\mathbf{a}}$ \\
\hline 2014 & 30 & 13 & 5 & & 91 & 27 & 19 \\
2015 & 28 & 12 & 4 & & 219 & 73 & 31 \\
2016 & 74 & 33 & 10 & & 215 & 135 & 47 \\
2017 & 58 & 24 & 10 & & 212 & 114 & 46 \\
\hline
\end{tabular}

a Number of potato varieties represents a conservative minimum, because not all sample lots reported varietal information when submitted for testing.
Potato variety source and PVY inoculum. Thirty potato varieties, in consecutive groups of four to six varieties, were grown in climate-controlled and insect-proof greenhouses year-round from 2014 to 2018 at the Agricultural Certification Services laboratory (Fredericton, NB, Canada). All varieties were grown from virusfree plantlets growing in agar with Murashige and Skoog basal salts as supplied by the Plant Propagation Center (Fredericton, NB, Canada) or, in the case of varieties Musica and Columba, as virus-free minitubers. Plantlets were hardened to the greenhouse conditions for several days before being transplanted into commercial potting soil in $15-\mathrm{cm}$ pots. Greenhouse conditions were maintained as constant as possible, at approximately $26^{\circ} \mathrm{C}$ (day) and $18^{\circ} \mathrm{C}$ (night) with approximately $14 \mathrm{~h} /$ day and $10 \mathrm{~h} /$ night (supplemented by artificial lighting when necessary). A minimum of 25 plants per variety was transplanted, allowing 5 plants for control (noninfected); 5 plants each infected with $\mathrm{PVY}$, $\mathrm{PVY}^{\mathrm{N}: \mathrm{O}}$, and $\mathrm{PVY}^{\mathrm{NTN}}$ strains; and 5 additional plants to use as replacements if needed. Potted plants were monitored daily, watered as necessary (typically every 2 days), and fertilized approximately every 2 weeks, alternating between 20:20: 20 (N:P:K) and 10:52:10 (N:P:K) (Plant-Prod).

$\mathrm{PVY}$ isolates used for inoculation were $\mathrm{PVY}^{\mathrm{O}}-\mathrm{FL}, \mathrm{PVY}^{\mathrm{N}: \mathrm{O}_{-}}$ Mb112, and PVY ${ }^{N T N}-S 1$ (B. Nie et al. 2011, 2012; X. Nie et al. 2004), which were maintained in tissue culture in varieties Shepody and Russet Norkotah. The strain identity of these inocula were confirmed regularly by multiplex PCR (Lorenzen et al. 2006) and DNA sequencing, and were also routinely ELISA screened for contamination by other common potato viruses, including Potato virus A, Potato virus $M$, Potato virus $S$, PVX, and Potato leafroll virus. Infected leaf tissue was taken from potted plants grown from tissue culture plantlets or known infected tubers harboring each PVY strain. Primary infection was accomplished by dusting three leaves per plant with carborundum powder (320 grit; Fisher Scientific Co.), then lightly rubbing the leaf with a ceramic pestle covered with freshly pulverized PVY-infected leaf tissue in chilled inoculation buffer ( $50 \mathrm{mM}$ glycine and $30 \mathrm{mM} \mathrm{K}_{2} \mathrm{HPO}_{4}, \mathrm{pH}$ 9.2). This was to mimic infection of the leaves naturally by aphids. Inoculations typically occurred at approximately 6 weeks after transplanting, when plants were 20 to $40 \mathrm{~cm}$ tall and had 10 to 15 leaves. Young, newly grown leaves of all inoculated and control plants were tested by ELISA (Singh et al. 2003) and PCR (Lorenzen et al. 2006) 2 weeks after inoculation to confirm PVY infection.

Observation of PVY symptoms. Growing plants were monitored regularly from planting until senescence, which typically occurred about 2 months following inoculation. During this period, specific visible foliar symptoms such as mosaic, leaf crinkling or rolling, leaf drop, plant stunting, or early senescence were noted, and photographic panels of whole plants and leaf details were made. All control and infected plants within each variety were cut down at the soil surface on the same day, and fresh plant tops immediately weighed as a quantitative measure of "plant vigor". Varieties were cut when control plants began showing signs of senescence, which varied across the varieties between 97 to 116 days from planted plantlets (primary generation) and 82 to 97 days from planted tubers (secondary generation). After cutting, tubers were allowed to mature in the dry soil pots for 2 to 3 weeks; then, tubers of each plant were dug up, counted, and weighed before being stored in an individual craft paper bag for each plant. During storage, tubers were inspected and compared every 4 to 6 weeks, and photographic panels were made.

After storage for 4 to 5 months, replicate tubers from each strain-variety combination were individually planted in pots for observation of symptoms from secondary (seed tuberborne) infection as described above for primary infection. The entire cycle of initial planting, primary infection, tuber harvest, secondary grow out, and final tuber storage typically took approximately 15 months for each variety.

A semiquantitative foliar "symptom severity scale" was calculated for each strain-variety combination for both primary and secondary infections. Foliar symptoms (Table 2) were each scored as 0 for absent, 0.5 for weak expression, and 1 for strong expression, then summed to a single numerical representation of symptom severity for each variety-strain combination; tuber symptoms were not 
included because they are not as easily assessed during the growing season in the field. This scale was used to compare symptom severity between strains, and to correlate visible foliar symptoms with tuber yield. More specifically than this scale, however, certain individual symptoms may be more associated than others with effects on tuber yield. Thus, individual symptom types "mosaic", "leaf deformation", and "leaf drop/early plant senescence" were also correlated with yield loss in all variety-strain combinations.

Table 2. Visual symptoms recorded from plants infected with Potato virus $Y(\mathrm{PVY})^{\mathrm{a}}$

\begin{tabular}{|c|c|c|c|c|c|c|}
\hline Variety & Mosaic & Chlorosis & Young leaflet deformation & Leaf drop & Early senescence & Plant stunting \\
\hline \multirow[t]{2}{*}{ AC Chaleur (PTNRD) } & O NTN & O NTN & ntn & o ntn & o ntn & O ntn \\
\hline & O N:O NTN & O N:O NTN & $\mathrm{ntn}$ & O ntn & O ntn & O NTN \\
\hline \multirow[t]{2}{*}{ Atlantic } & o N:O ntn & $\ldots$ & O N:O ntn & $\mathrm{O}$ & $\ldots$ & $\ldots$ \\
\hline & o N:O ntn & $\ldots$ & $\mathrm{O} \mathrm{N}: \mathrm{O}$ ntn & $\ldots$ & $\ldots$ & $\ldots$ \\
\hline \multirow[t]{2}{*}{ Beljade } & O N:O NTN & $\ldots$ & o n:o & $\ldots$ & $\ldots$ & $\mathrm{O}$ \\
\hline & O n:o NTN & $\ldots$ & o n:o & $\ldots$ & $\ldots$ & NTN \\
\hline \multirow[t]{2}{*}{ Bintje } & o & $\ldots$ & o N:O ntn & $\ldots$ & $\ldots$ & $\ldots$ \\
\hline & $\ldots$ & $\ldots$ & o N:O ntn & $\ldots$ & $\ldots$ & $\ldots$ \\
\hline \multirow[t]{2}{*}{ Blazer Russet } & $\mathrm{N}: \mathrm{O}$ & o & o N:O & $\ldots$ & $\ldots$ & $\ldots$ \\
\hline & $\ldots$ & o & o n:o & $\ldots$ & $\ldots$ & $\ldots$ \\
\hline \multirow[t]{2}{*}{ Chieftain } & o N:O NTN & $\mathrm{O}$ & O N:O NTN & $\mathrm{O}$ & $\ldots$ & $\mathrm{ntn}$ \\
\hline & o N:O NTN & $\mathrm{O}$ & o n:o & $\ldots$ & $\ldots$ & $\ldots$ \\
\hline \multirow[t]{2}{*}{ Classic Russet } & $\ldots$ & n:o ntn & o n:o ntn & o ntn & o & o \\
\hline & $\ldots$ & $\ldots$ & o & $\mathrm{O}$ & $\mathrm{O}$ & O n:o ntn \\
\hline \multirow[t]{2}{*}{ Clearwater Russet } & $\ldots$ & $\mathrm{n}: \mathrm{o}$ & o ntn & $\ldots$ & $\ldots$ & $\ldots$ \\
\hline & $\ldots$ & $\ldots$ & o ntn & $\mathrm{O}$ & $\ldots$ & $\ldots$ \\
\hline \multirow[t]{2}{*}{ Columba } & n:o & $\mathrm{n}: \mathrm{o}$ & n:o & $\ldots$ & $\ldots$ & $\mathrm{n}: \mathrm{o}$ \\
\hline & o n:o ntn & n:o & O n:o ntn & $\ldots$ & $\ldots$ & o n:o ntn \\
\hline \multirow[t]{2}{*}{ Dakota Pearl } & $\mathrm{O} \mathrm{N}: \mathrm{O}$ & $\mathrm{O}$ n:o & O ntn & O n:o & $\mathrm{O}$ & $\mathrm{O}$ \\
\hline & $\mathrm{O}$ & O n:o & $\mathrm{O}$ & O n:o & $\mathrm{O}$ & o \\
\hline \multirow[t]{2}{*}{ Envol (PTNRD) } & $\mathrm{O}$ & $\mathrm{O}$ & $\mathrm{O} \mathrm{N}: \mathrm{O}$ ntn & O n:o ntn & $\mathrm{O}$ & O n:o NTN \\
\hline & $\mathrm{O}$ & $\mathrm{O}$ & O n:o ntn & O n:o ntn & $\mathrm{O}$ & O n:o NTN \\
\hline \multirow[t]{2}{*}{$\mathrm{Eva}^{\mathrm{b}}$} & $\ldots$ & $\ldots$ & $\ldots$ & $\ldots$ & $\ldots$ & $\ldots$ \\
\hline & & $\ldots$ & & $\ldots$ & $\ldots$ & o ntn \\
\hline \multirow[t]{2}{*}{ Gem Russet } & O N:O ntn & $\mathrm{n}: \mathrm{o}$ & O N:O NTN & $\ldots$ & $\ldots$ & $\ldots$ \\
\hline & o n:o ntn & n:o & o N:O & $\ldots$ & $\ldots$ & o \\
\hline \multirow[t]{2}{*}{ Innovator } & o n:o & $\ldots$ & o n:o & $\ldots$ & $\ldots$ & $\ldots$ \\
\hline & o n:o & $\ldots$ & o n:o & $\ldots$ & $\ldots$ & $\ldots$ \\
\hline \multirow[t]{2}{*}{ Ivory Russet } & $\ldots$ & $\ldots$ & $\ldots$ & O n:o ntn & $\ldots$ & $\ldots$ \\
\hline & o n:o ntn & $\ldots$ & $\ldots$ & O n:o ntn & $\ldots$ & $\ldots$ \\
\hline \multirow[t]{2}{*}{ Monticello } & o N:O ntn & $\ldots$ & $\mathrm{O} \mathrm{N}: \mathrm{O}$ ntn & $\ldots$ & $\ldots$ & $\mathrm{ntn}$ \\
\hline & o n:o ntn & $\ldots$ & $\ldots$ & $\ldots$ & $\ldots$ & $\ldots$ \\
\hline Musica $^{\text {b }}$ & $\ldots$ & $\ldots$ & $\ldots$ & $\ldots$ & $\ldots$ & $\mathrm{ntn} \ldots$ \\
\hline Norchip & o ntn & $\ldots$ & o ntn & $\ldots$ & $\ldots$ & o n:o ntn \\
\hline & o ntn & $\ldots$ & o ntn & $\ldots$ & $\ldots$ & O ntn \\
\hline Norland & O n:o ntn & $\ldots$ & n:o ntn & $\mathrm{O}$ & $\mathrm{O}$ & O N:O NTN \\
\hline & O n:o ntn & $\ldots$ & $\ldots$ & $\mathrm{O}$ & $\mathrm{O}$ & $\mathrm{O}$ \\
\hline Pacific Russet (PTNRD) & $\ldots$ & n:o ntn & $\ldots$ & $\mathrm{O}$ & $\mathrm{O}$ & O n:o \\
\hline & $\mathrm{N}: \mathrm{O}$ & n:o ntn & $\ldots$ & $\ldots$ & $\ldots$ & O n:o \\
\hline Ranger Russet & o n:o & o n:o & O n:o ntn & O N:O NTN & $\mathrm{O}$ & $\mathrm{O}$ \\
\hline & $\mathrm{O} \mathrm{N}: \mathrm{O}$ ntn & o n:o & o n:o & o N:O NTN & $\ldots$ & $\ldots$ \\
\hline Redsen & n:o ntn & n:o ntn & o n:o ntn & $\ldots$ & $\ldots$ & $\ldots$ \\
\hline & N:O NTN & n:o ntn & O N:O NTN & $\ldots$ & $\ldots$ & o N:O \\
\hline Sangre & $\mathrm{O} \mathrm{N}: \mathrm{O}$ ntn & o & O n:o ntn & o & $\ldots$ & $\ldots$ \\
\hline & o N:O & $\ldots$ & o N:O & $\ldots$ & $\ldots$ & $\mathrm{N}: \mathrm{O}$ ntn \\
\hline Shepody & n:o ntn & $\ldots$ & o N:O ntn & $\ldots$ & $\ldots$ & $\ldots$ \\
\hline & n:o & $\ldots$ & o n:o & $\ldots$ & $\ldots$ & $\ldots$ \\
\hline Snowden & n:o ntn & $\ldots$ & $\mathrm{O} N: O$ ntn & O n:o ntn & $\ldots$ & $\ldots$ \\
\hline & $\ldots$ & $\ldots$ & o & $\ldots$ & $\ldots$ & $\ldots$ \\
\hline Tenace & o N:O ntn & o & o n:o ntn & $\mathrm{O}$ & $\ldots$ & O n:o ntn \\
\hline & $\mathrm{O} \mathrm{N}: \mathrm{O}$ & o & O n:o & $\mathrm{O}$ & $\ldots$ & n:o \\
\hline Umatilla Russet & O n:o ntn & $\cdots$ & o n:o ntn & o & $\ldots$ & O n:o ntn \\
\hline & o N:O NTN & $\ldots$ & o N:O NTN & $\ldots$ & $\ldots$ & $\ldots$ \\
\hline Viking & o N:O & $\ldots$ & n:o & $\ldots$ & $\ldots$ & $\ldots$ \\
\hline & o n:o & $\ldots$ & $\mathrm{n}: \mathrm{o}$ & $\ldots$ & $\ldots$ & $\ldots$ \\
\hline Yukon Gold (PTNRD) & o N:O NTN & $\mathrm{ntn}$ & o n:o ntn & O ntn & $\ldots$ & $\ldots$ \\
\hline & o N:O NTN & ntn & O N:O NTN & O ntn & $\cdots$ & O NTN \\
\hline Satina ${ }^{c}$ & $\mathrm{~N}: \mathrm{O}$ ntn & $\ldots$ & $\mathrm{O} \mathrm{N}: \mathrm{O}$ ntn & $\mathrm{O}$ & $\begin{array}{l}\cdots \\
\cdots\end{array}$ & O N:O NTN \\
\hline
\end{tabular}

a Symptom noted in $\mathrm{PVY}^{\mathrm{O}}(\mathrm{O}, \mathrm{o}), \mathrm{PVY}^{\mathrm{N}: \mathrm{O}}(\mathrm{N}: \mathrm{O}, \mathrm{n}: \mathrm{o})$, or PVYNTN $(\mathrm{NTN}, \mathrm{ntn})$; uppercase strain designation $(\mathrm{O}, \mathrm{N}: \mathrm{O}, \mathrm{NTN})$ indicates strong expression of symptom and lowercase (o, n:o, ntn) indicates weak but observed symptom. Upper tier in each variety row indicates symptoms from primary infection and lower tier from secondary infection. Varieties in this study which exhibited potato tuber necrotic ringspot disease (PTNRD) symptoms from PVY ${ }^{\mathrm{NTN}}$ infection are indicated with the variety name.

${ }^{b}$ Varieties Eva and Musica showed complete resistance to PVY infection with all three strains (virus undetected with enzyme-linked immunosorbent assay or polymerase chain reaction).

${ }^{c}$ Variety Satina only observed after primary infection. 
Data analysis. Data were sorted, and descriptive statistics (mean, standard error, and so on) were calculated with Excel for Mac 2011 (v. 14.4.0; Microsoft Corporation). Statistical tests were performed with the included StatPlus:Mac LE package (v. 5.9.5.0; AnalystSoft, Inc.). Figures were produced with Excel and converted to appropriate format and resolution with GraphicConverter 9 (v. 9.7.6; Lemke Software $\mathrm{GmbH}$ ).

\section{Results}

Recent changes in PVY strains in different potato production regions of Canada. Relative populations of PVY strains were remarkably different in western and eastern regions of Canada, and changed substantially in both, during the 4-year study period (Fig. 1). In eastern Canada in 2014, $\mathrm{PVY}^{\mathrm{O}}$ was predominant (49\% of all tested PVY) but nearly equal in proportion to PVY ${ }^{\mathrm{NTN}}$ (42\%), with only $9 \% \mathrm{PVY}^{\mathrm{N}: \mathrm{O} / \mathrm{N}-\mathrm{Wi}}$. Over the following years, to 2017, $\mathrm{PVY}^{\mathrm{O}}$ dropped progressively to $11 \%$ of sampled PVY, almost exclusively replaced by $\mathrm{PVY}^{\mathrm{NTN}}$ (which rose to $75 \%$ ); $\mathrm{PVY}^{\mathrm{N}: \mathrm{O} / \mathrm{N}-\mathrm{Wi}}$ fluctuated between 9 and $23 \%$ over these 4 years. This confirms, in a broader and more comprehensive survey, an earlier PVY strain survey between 2010 and 2016 restricted only to the eastern Canadian province of New Brunswick (MacKenzie et al. 2018). In western Canada in 2014, all three strains were essentially equally represented from 30 to $37 \%$, and were more variable in the following years than the isolates acquired from eastern Canada. By 2017, however, $\mathrm{PVY}^{\mathrm{N}}$ : O/N-Wi clearly came to dominate the PVY samples at $70 \%$, followed by $25 \% \mathrm{PVY}^{\mathrm{NTN}}$ and only $5 \% \mathrm{PVY}^{\mathrm{O}}$. Rarely, dual infections by different PVY strains cooccurred in the same plant sample, though all combinations of coinfection by two different strains under the Lorenzen method produce a characteristic pattern of PCR products. In these few identified cases, each was counted as a unique infection event, regardless of whether that viral strain occurred in one plant or two.

Of $113 \mathrm{PVY}^{\mathrm{N}: \mathrm{O} / \mathrm{N}-\mathrm{Wi}}$ samples identified by the Lorenzen et al. (2006) protocol, when using the alternative Chikh Ali et al. (2010) multiplex PCR protocol, 40 of 42 (95\%) from western Canada were confirmed to be PVYN-Wi , while only 39 of $71(55 \%)$ in eastern Canada were $\mathrm{PVY} \mathrm{N}^{\mathrm{N}-\mathrm{Wi}}$, with all others positively identified as $\mathrm{PVY}^{\mathrm{N}: \mathrm{O}}$.

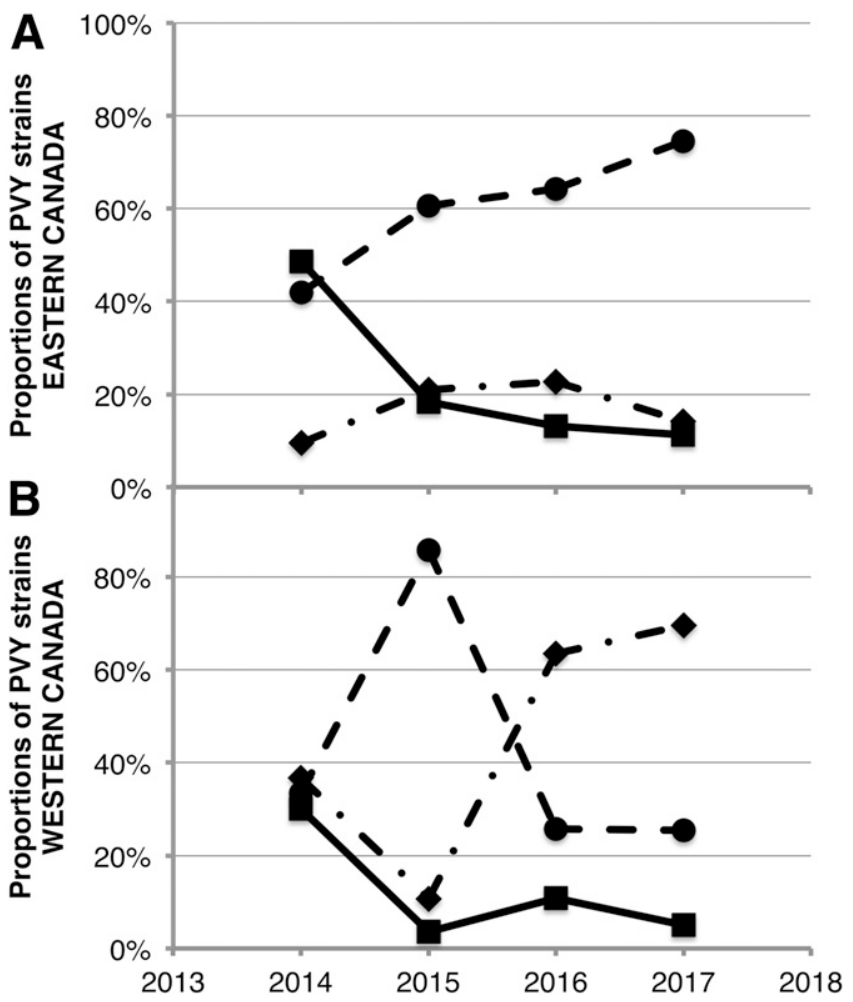

Fig. 1. Proportions of Potato virus $Y(P V Y)$ strains $P V Y^{O}, P V Y^{N}: O / N-W i$, and $P V Y^{N T N}$ (circles, dashed line) for $\mathbf{A}$, eastern Canada and $\mathbf{B}$, western Canada.
To cross-check the identity of PVY ${ }^{\mathrm{O}}$ and PVY ${ }^{\mathrm{NTN}}$ samples determined by the Lorenzen et al. (2006) protocol, 6 and 34 of these samples were taken from both regions and all confirmed with Chikh-Ali et al. (2013) to properly be PVY ${ }^{\mathrm{O}}$ and $\mathrm{PVY}^{\mathrm{NTN}}(\mathrm{A})\left(=\mathrm{Eu}-\mathrm{PVY}^{\mathrm{NTN}}\right)$, respectively.

Typical foliar symptoms expressed by three PVY strains across 30 potato varieties. A wide range of symptoms were expressed across the 30 varieties infected with different PVY strains, including mosaic coloration of the leaves, stunting, rugose surface and crinkling or rolling of the margins of leaflets, localized chlorotic and necrotic spots, leaf dropping, plant stunting, and early senescence. Examples of each of these symptoms are shown in Figure 2 and a comprehensive catalog of visible foliar and tuber symptoms is presented in Table 2.

The traditionally most important diagnostic symptom of PVY infection, a characteristic mosaic coloration of the leaves, was not evident in all PVY strain-potato variety combinations in this study. Of the 30 varieties studied, 20, 23, and 18 varieties showed some visible mosaic in either primary or secondary infection with $\mathrm{PVY}^{\mathrm{O}}, \mathrm{PVY}^{\mathrm{N}: \mathrm{O}}$, and PVY ${ }^{\mathrm{NTN}}$, respectively. These symptoms were typically most pronounced on young apical leaves, though they varied in severity and consistency between primary and secondary infection. $\mathrm{PVY}^{\mathrm{O}}$ infection generally showed stronger mosaic symptoms than other strains in susceptible varieties. Although $\mathrm{PVY} \mathrm{N}^{\mathrm{N}: \mathrm{O}}$ showed the greatest number of occurrences of mosaic in the study, these were more often relatively mild compared with $\mathrm{PVY}^{\mathrm{O}}$, or either in primary or secondary infection. Overall, $\mathrm{PVY}^{\mathrm{O}}$ and $\mathrm{PVY}^{\mathrm{N}: \mathrm{O}}$ elicited mosaic in more varieties than $\mathrm{PVY}^{\mathrm{NTN}}$ and, as with $\mathrm{PVY}^{\mathrm{N}: \mathrm{O}}, \mathrm{PVY}^{\mathrm{NTN}}$ infection typically showed weaker mosaic in either primary or secondary infection.

Other than the varieties Eva and Musica, which are known or suspected to possess $R y$ genes and, thus, exhibit extreme resistance to PVY (Valkonen et al. 2017; van Eck et al. 2017), only two other varieties (Classic Russet and Clearwater Russet) did not show mosaic with any strains; and, in two more varieties, it only occurred from infection by one of the three strains (AC Chaleur with $\mathrm{PVY}^{\mathrm{N}: \mathrm{O}}$ and Bintje with $\mathrm{PVY}^{\mathrm{O}}$ ). When only considering mosaic symptoms scored as "strong", which visually would be easily identifiable in the field, the number showing it from infection by all three strains dropped to only three varieties (Beljade, Chieftain, and Umatilla Russet). Details on which varieties, what type of infection (primary versus secondary), and the relative severity of mosaic symptoms are shown in Table 2.

Another group of symptoms common to PVY infection, though not limited to this virus, are several types of leaf deformation such as leaflet stunting and marginal crinkling, especially in young apical leaves. Again, although not all potato varieties tested showed notable leaf deformation compared with uninfected control plants, these symptoms were more consistent across PVY strains than the mosaic coloration. Under primary or secondary infection with $\mathrm{PVY}^{\mathrm{O}}, \mathrm{PVY}^{\mathrm{N}: \mathrm{O}}$, and PVYNTN $, 23,22$, and 22 varieties, respectively, showed some visible amount of leaflet deformation in new leaf growth. In addition to being consistent in number, most of the specific varieties showing leaflet deformation were susceptible across PVY strains; 23 varieties showed these symptoms with either two or all three PVY strains, and only 3 varieties showed leaflet deformation with only one strain.

A further major visible symptom of PVY infection (again not exclusive to this virus, however) was premature leaf drop and early plant senescence. This response to infection was far more common with $\mathrm{PVY} \mathrm{O}^{\mathrm{O}}$ than other symptoms. Under primary or secondary infection, leaf drop coded as either relatively weak or strong was present in 16,6 , and 7 varieties in $\mathrm{PVY}^{\mathrm{O}}, \mathrm{PVY}^{\mathrm{N}: \mathrm{O}}$, and $\mathrm{PVY}^{\mathrm{NTN}}$, respectively. Most of the varieties showing leaf drop from $\mathrm{PVY}^{\mathrm{O}}$, however, showed it following primary infection, with only five varieties showing it in both primary and secondary infection. Conversely, in the fewer varieties showing leaf drop in plants infected with $\mathrm{PVY}^{\mathrm{N}: \mathrm{O}}$ and PVY ${ }^{\mathrm{NTN}}$, it was more likely to occur in both primary and secondary infection in all but one variety with $\mathrm{PVY}^{\mathrm{N}: \mathrm{O}}$ and two varieties with PVY ${ }^{\text {NTN }}$.

Effects of PVY strain infection on plant growth, tuber yield, and quality. For all virus strains after primary infection, plant vigor 
(measured by aboveground plant biomass immediately before harvest) was significantly reduced from uninfected controls when all varieties were averaged together (Table 3; Fig. 3A; paired $t$ test, $P$ values $10^{-3}$ to 0.01$)$. $\mathrm{PVY}^{\mathrm{O}}, \mathrm{PVY}^{\mathrm{N}: \mathrm{O}}$, and $\mathrm{PVY}^{\mathrm{NTN}}$ primary infection reduced aboveground plant biomass by 27,11 , and $11 \%$, respectively. In plants grown from these tubers, secondary (seed tuberborne) PVY infection reduced vigor less severely than primary infection, averaging 19,6 , and $8 \%$, respectively, with only $\mathrm{PVY}^{\mathrm{O}}$ infection causing statistically significant plant biomass reduction as a result of secondary infection (paired $t$ test, $P=0.001$ ). Relative to uninfected control plants, reduction in plant biomass correlated well between primary and secondary infection across PVYO and PVY ${ }^{\mathrm{NTN}}$

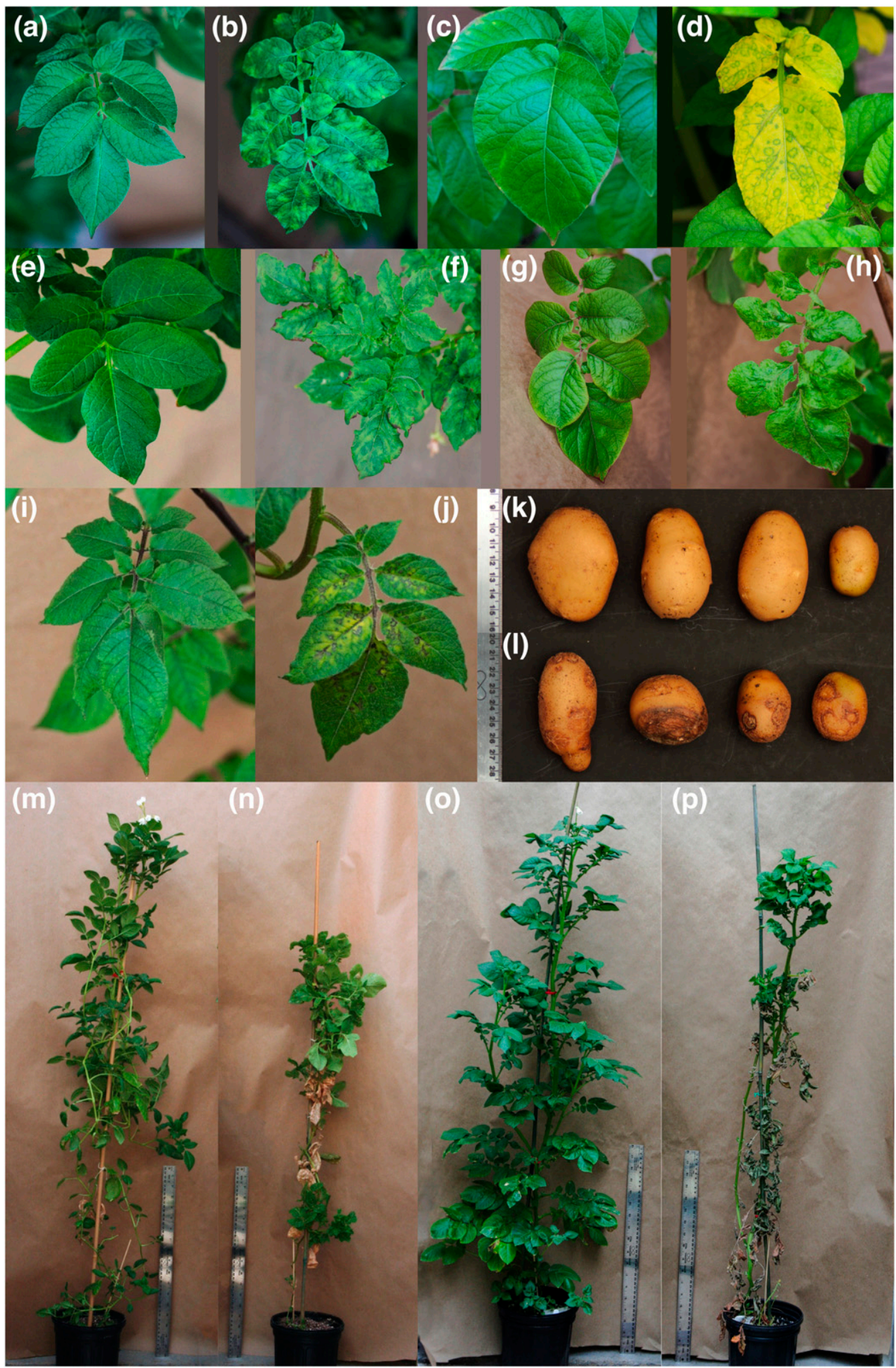

Fig. 2. Example symptoms expressed across a range of potato varieties. Mosaic in a, Umatilla Russet (control) and b, Potato virus $Y(P V Y)^{\mathrm{N}: \mathrm{O}}$ infected; annular spots in $\mathbf{c}$, Yukon

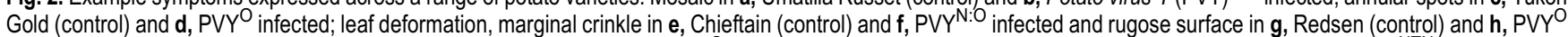
infected; chlorosis with necrotic spots in $\mathrm{i}$, Classic Russet (control) and j, PVYO infected; necrotic ringspots in tubers in $\mathbf{k}$, AC Chaleur (control) and I, PVYNTN infected; plant stunting in $\mathbf{m}$, Tenace (control) and $\mathbf{n}, \mathrm{PVY}^{\mathrm{O}}$ infected; and leaf drop with early senescence in $\mathbf{0}$, Pacific Russet (control) and $\mathbf{p}, \mathrm{PVY}^{\mathrm{O}}$ infected. For the purposes of this study, "annular spots" was included as a form of mosaic. 
(least-squares linear regression $P$ values approximately 0.0001 and 0.02 , respectively) but not $\mathrm{PVY}^{\mathrm{N}: \mathrm{O}}(P=0.48)$.

Tuber yield under primary and secondary infection showed a roughly similar pattern to that of reduction of plant vigor, though yield was proportionately more impacted than vigor. Tuber yield was reduced 33,15 , and $16 \%$ due to primary infection with $\mathrm{PVY}^{\mathrm{O}}$, $\mathrm{PVY}^{\mathrm{N}: \mathrm{O}}$, and PVY ${ }^{\mathrm{NTN}}$ and 22,10 , and $3 \%$ under secondary infection with these strains, respectively (Table 3 ; Fig. $3 \mathrm{~B} ; P$ values $10^{-6}$ to 0.001 for primary infection and $10^{-4}$ to 0.05 for secondary infection). Despite the similarity of pattern in the mean reduction of plant biomass (vigor) and tuber yield, these were only clearly correlated with $\mathrm{PVY}^{\mathrm{O}}$ for both primary and secondary infection (least-squares linear regression $P=0.00005$ and 0.0001 , respectively), and PVY ${ }^{\text {NTN }}$ only in secondary infection $(P=0.026)$.

A major concern about infection with PVYNTN is the potential for tuber necrosis (PTNRD); however, these symptoms were observed in only four varieties: AC Chaleur, Envol, Pacific Russet, and Yukon Gold. Examples of these tuber necroses are shown in Figure 2(l) and, when present in a variety, they affected the majority of the tubers produced from an infected plant. These necrotic ringspots were generally visible at harvest but intensified during storage, with ringspots darkening and spreading and with the skin often roughening, splitting, and exfoliating. This breaching of the skin often led to drying or rotting of the tuber after several months of storage. Also, these symptoms were generally more pronounced in secondary than in primary infection. Compared with non-PTNRD tubers, yields of necrosis-susceptible plants were lower (6\% lower yield on average in primary infection and $40 \%$ in secondary). It was not clear that the tuber necroses themselves or a general decline in plant health caused lowered yield in susceptible plants, because the foliar symptoms and plant vigor were also more heavily impacted than nonPTNRD-susceptible plants.

Correlation of visual symptoms with yield loss across potato varieties. Symptom severity scale scores varied widely across variety and strain of infection although, on average, $\mathrm{PVY}{ }^{\mathrm{O}}$ generated the highest. Excluding the resistant varieties Eva and Musica, which showed no symptoms and were unable to be infected with PVY (no visible symptoms and negative by ELISA and PCR tests), several PVY-susceptible varieties also showed no symptoms after infection with particular PVY strains. These varieties scoring zero on a symptom severity scale included Norchip with PVY ${ }^{\mathrm{N}: \mathrm{O}}$ and Blazer Russet, Innovator, and Viking with PVY ${ }^{\mathrm{NTN}}$. At the opposite extreme, the highest symptom severity score calculated was 6 , from variety Envol infected with $\mathrm{PVY}^{\mathrm{O}}$. Across all variety-strain combinations, the average symptom severity score was 1.29 . When grouped by PVY strain and infection route, however, $\mathrm{PVY}{ }^{\mathrm{O}}$-infected plants averaged 1.91 and 1.58 for primary and secondary infection, $\mathrm{PVY}^{\mathrm{N}: \mathrm{O}} 1.39$ and 1.19 , and PVY ${ }^{\mathrm{NTN}} 0.97$ and 0.69 , respectively across all varieties.

To assess whether visual symptoms were predictive of tuber yield loss, symptom severity scores were correlated with yield (Fig. 4). In all varieties together, yield relative to uninfected control plants showed significant negative correlation with symptom severity score for primary and secondary infection $\left(P\right.$ values $4.3 \times 10^{-4}$ and $2.0 \times$ $10^{-7}$, respectively). Looking at the extremes of distribution of symptom severity and variety-PVY strain combinations, $\mathrm{PVY}^{\mathrm{NTN}}$ infections

Table 3. Changes in plant vigor (aboveground plant biomass) and tuber yield (mass of all tubers produced per plant) in plants infected with three Potato virus $Y$ (PVY) strains relative to uninfected plants of the same variety grown simultaneously under the same conditions ${ }^{\mathrm{a}}$

\begin{tabular}{|c|c|c|c|c|c|c|c|c|c|c|c|c|}
\hline \multirow[b]{3}{*}{ Variety } & \multicolumn{6}{|c|}{ Plant vigor (\% change) } & \multicolumn{6}{|c|}{ Tuber yield (\% change) } \\
\hline & \multicolumn{2}{|c|}{ PVYO } & \multicolumn{2}{|c|}{ PVY ${ }^{N: O}$} & \multicolumn{2}{|c|}{ PVYNTN } & \multicolumn{2}{|c|}{ PVYO } & \multicolumn{2}{|c|}{ PVY $^{\mathrm{N}: \mathrm{O}}$} & \multicolumn{2}{|c|}{ PVYNTN } \\
\hline & Pri & Sec & Pri & Sec & Pri & Sec & Pri & Sec & Pri & Sec & Pri & Sec \\
\hline AC Chaleur & -53 & -45 & -8 & -15 & -28 & -38 & -28 & -52 & -25 & -27 & -53 & -69 \\
\hline Atlantic & 2 & 6 & -2 & 27 & 12 & 19 & -29 & 26 & -5 & 34 & -6 & 22 \\
\hline Beljade & -36 & -10 & -7 & 1 & -6 & -40 & -48 & -29 & -9 & -19 & -10 & -29 \\
\hline Bintje & 6 & -6 & -3 & 25 & 28 & 12 & -1 & 22 & -6 & -8 & -19 & 23 \\
\hline Blazer Russet & -2 & 16 & 2 & 8 & 3 & 3 & -26 & -4 & -6 & 0 & 4 & 2 \\
\hline Chieftain & 11 & -7 & -8 & 13 & -21 & -16 & -28 & -15 & -9 & 4 & -9 & 29 \\
\hline Classic Russet & -28 & -45 & 5 & -22 & 0 & -28 & -54 & -42 & -36 & -5 & -46 & 11 \\
\hline Clearwater Russet & -16 & 26 & -4 & 31 & -6 & 69 & -18 & 19 & -31 & -3 & -27 & 16 \\
\hline Columba & 2 & -27 & -21 & -25 & -4 & -31 & 11 & 17 & 0 & -2 & 10 & 11 \\
\hline Dakota Pearl & -44 & -31 & -9 & 35 & 5 & 30 & -36 & -41 & -19 & 0 & -25 & 5 \\
\hline Envol & -100 & -93 & -26 & -27 & -64 & -92 & -67 & -79 & 72 & 9 & 4 & -47 \\
\hline $\mathrm{Eva}^{\mathrm{b}}$ & -8 & -27 & 13 & -7 & -8 & -31 & -63 & -23 & -8 & 8 & -26 & -23 \\
\hline Gem Russet & 2 & -32 & 11 & -4 & 4 & -7 & -45 & -49 & -55 & 29 & -17 & 11 \\
\hline Innovator & -4 & -9 & -6 & 21 & -2 & -3 & -14 & -46 & -18 & -79 & -10 & -24 \\
\hline Ivory Russet & 2 & -4 & -10 & -5 & 17 & -3 & -35 & -21 & -25 & -15 & -30 & -16 \\
\hline Monticello & -19 & 1 & -10 & -10 & -24 & -7 & -33 & -1 & -11 & -3 & 9 & 3 \\
\hline Musica $^{\text {b }}$ & -12 & 20 & -18 & 2 & -24 & -9 & -4 & -1 & 11 & -8 & 5 & -8 \\
\hline Norchip & -32 & -41 & -26 & -11 & -23 & -20 & -13 & 11 & -22 & 38 & -37 & 6 \\
\hline Norland & -100 & -57 & -37 & -10 & -41 & 18 & -80 & -90 & 15 & -20 & 7 & -8 \\
\hline Pacific Russet & -64 & -52 & -23 & -30 & -14 & -17 & -45 & -21 & -29 & -6 & -2 & -9 \\
\hline Ranger Russet & -89 & -18 & -16 & -9 & -18 & -10 & -50 & -55 & -12 & -31 & -32 & -16 \\
\hline Redsen & -8 & -30 & -1 & -61 & -15 & -14 & -3 & -30 & -3 & -26 & -6 & -23 \\
\hline Sangre & -4 & -12 & -8 & -37 & 21 & -23 & -24 & -33 & -9 & -13 & -19 & 10 \\
\hline Shepody & 10 & 7 & 21 & -17 & 14 & 41 & -35 & -26 & -35 & -50 & -45 & -29 \\
\hline Snowden & -15 & -3 & -18 & -1 & -13 & -17 & -8 & 0 & -19 & -11 & 4 & 25 \\
\hline Tenace & -62 & -13 & -23 & -27 & -33 & 16 & -61 & -18 & -43 & -33 & -35 & 38 \\
\hline Umatilla Russet & -51 & 2 & -31 & -3 & -32 & -10 & -43 & -22 & -6 & -12 & -10 & -17 \\
\hline Viking & -8 & -6 & -7 & -9 & -10 & 6 & -8 & 3 & -20 & 2 & 0 & 15 \\
\hline Yukon Gold & -12 & -36 & 1 & -13 & -19 & -46 & -56 & -25 & -11 & -15 & -33 & -31 \\
\hline Satina & -54 & $\ldots$ & -35 & $\ldots$ & -38 & $\ldots$ & -53 & $\ldots$ & -39 & $\ldots$ & -21 & $\ldots$ \\
\hline Mean $^{\mathrm{b}}$ & -27.4 & -19.2 & -11.0 & -6.5 & -11.3 & -7.7 & -33.2 & -22.3 & -14.9 & -9.7 & -16.2 & -3.4 \\
\hline
\end{tabular}

${ }^{a}$ Negative values indicate reductions (in percent) from uninfected control plants; "Pri" and "Sec" indicate vigor or yield difference under primary and secondary infection, respectively.

${ }^{\mathrm{b}}$ Varieties Eva and Musica were absolutely resistant to PVY infection; thus, they are not included in the means for plant vigor and tuber yield reduction. 
dominated the least extreme symptom responses and yield reduction, while $\mathrm{PVY} \mathrm{O}^{\mathrm{O}}$ infections dominated the most severe. Taking the lowest quartile of symptom severity scores, yield reduction averaged $14 \%$ in primary and, unexpectedly, increased $5 \%$ in secondary infection, with PVY ${ }^{\mathrm{NTN}}$ accounting for more of these low-symptom, highyield occurrences than the other strains combined (56\% PVY ${ }^{\text {NTN }}$ occurrences versus $26 \% \mathrm{PVY}^{\mathrm{N}: \mathrm{O}}$ and $18 \% \mathrm{PVY}^{\mathrm{O}}$ ). Conversely, in the highest quartile of symptom severity scores, yield reduction was 42 and $32 \%$ in primary and secondary infection, respectively with PVYNTN accounting for only $11 \%$ of strain-variety combinations, $\mathrm{PVY}^{\mathrm{N}: \mathrm{O}}$ for $32 \%$, and $\mathrm{PVY}^{\mathrm{O}}$ for $57 \%$.

Given the strong dependence of tuber yield on PVY strain, correlations of yield and symptom severity were grouped by strain in Figure 4. Under both primary and secondary infection, visual symptom severity with $\mathrm{PVY} \mathrm{Y}^{\mathrm{O}}$ infection was strongly correlated with reduction in tuber yield (least-squares linear regression $P$ values 0.013 and 0.0007 , respectively). Symptoms from PVY ${ }^{\mathrm{NTN}}$ were more marginally significant ( $P$ values 0.078 and 0.005 for primary and secondary infection, respectively). In $\mathrm{PVY}^{\mathrm{N}: \mathrm{O}}$, despite often clear and strong foliar symptoms, symptom severity was not correlated at all with tuber yield loss ( $P$ values 0.97 and 0.37 ).

Relative tuber yields were grouped by three major symptoms-(i) mosaic, (ii) leaf deformation, and (iii) leaf drop or early senescence (Fig. 5) - to assess whether individual symptoms were associated with reduced tuber yield and, thus, whether these symptoms could be indicative of yield loss. With the most diagnostic symptom of PVY infection, mosaic coloration of leaves, only plants showing relatively strong mosaic and with $\mathrm{PVY} \mathrm{Y}^{\mathrm{O}}$ had substantial yield reduction as a group (Fig. 5A; 46 and 54\% below control in primary and secondary infection, respectively). Strong mosaic symptoms in PVY ${ }^{\mathrm{N}: \mathrm{O}}$ and PVY ${ }^{\text {NTN }}$ resulted in an average of only 20 to $24 \%$ reduction in yield, not much more than the average yield reduction of any PVY infection in any variety regardless of symptoms (Fig. 5A, approximately $18 \%$, indicated by dashed line). Symptoms categorized as "weak mosaic" resulted in only 29 and $11 \%$ yield reduction with $\mathrm{PVY}^{\mathrm{O}}$ in primary and secondary infection, respectively, and ranged

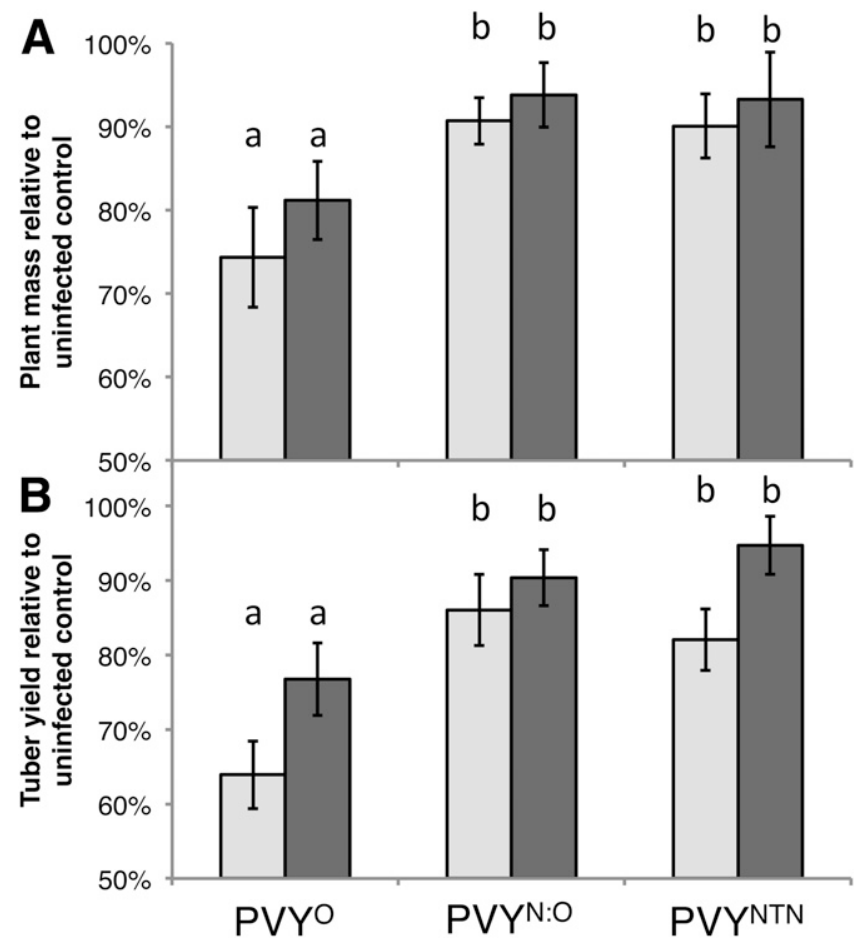

Fig. 3. Effects of infection by three Potato virus $Y$ (PVY) strains averaged across potato varieties on $\mathbf{A}$, aboveground plant biomass and $\mathbf{B}$, tuber yield. Effects of primary infection (light gray; 30 varieties, 5 plants each) and secondary infection (dark gray; 29 varieties, 4 plants each) are shown. Values are means \pm standard error of the mean. between 1 and 19\% yield reduction in other strains and types of infection.

When grouping varieties by strong, weak, or no leaf deformation, no pattern within PVY strains was evident across severity of the symptom (Fig. 5B). Although yield reduction was strongest, as expected, with $\mathrm{PVY}{ }^{\mathrm{O}}$ infection, there was no significant difference in yield reduction between strong, weak, or absent leaf deformation. Similarly with the other strains, which overall showed less yield reduction, there was no difference between levels of severity of the leaf deformation symptom. Also, on average, yield loss was slightly less with secondary infection than primary but there was no correspondence with severity of leaf deformation.

Finally, grouping varieties by presence or absence of leaf drop or early senescence again showed a clear pattern of response only with $\mathrm{PVY}^{\mathrm{O}}$ infection (Fig. 5C). Varieties showing leaf drop symptoms with $\mathrm{PVY} \mathrm{O}^{\mathrm{i}}$ infection averaged 42 and $36 \%$ lowered tuber yield in primary and secondary infection, respectively, approximately double that of $\mathrm{PVY}^{\mathrm{O}}$-infected varieties that did not show this symptom. $\mathrm{PVY}^{\mathrm{N}: \mathrm{O}}$-infected varieties with leaf drop symptoms did not show significantly less yield than the control or different yield than infected varieties that did not show leaf drop. PVY ${ }^{\mathrm{NTN}}$-infected plants only showed substantially lower tuber yield with leaf drop symptoms in secondary infection. With primary infection, yield loss averaged the same regardless of leaf drop, and was equal to the average yield loss across all infected varieties.

From the 30 varieties studied here, several were notable for having relatively strong visible symptoms for identification of infection yet relatively mild yield reductions. Specific examples included Atlantic, which showed diverse symptoms, including mosaic, especially in $\mathrm{PVY}^{\mathrm{N}: \mathrm{O}}$, while exhibiting less yield loss than most other varieties.

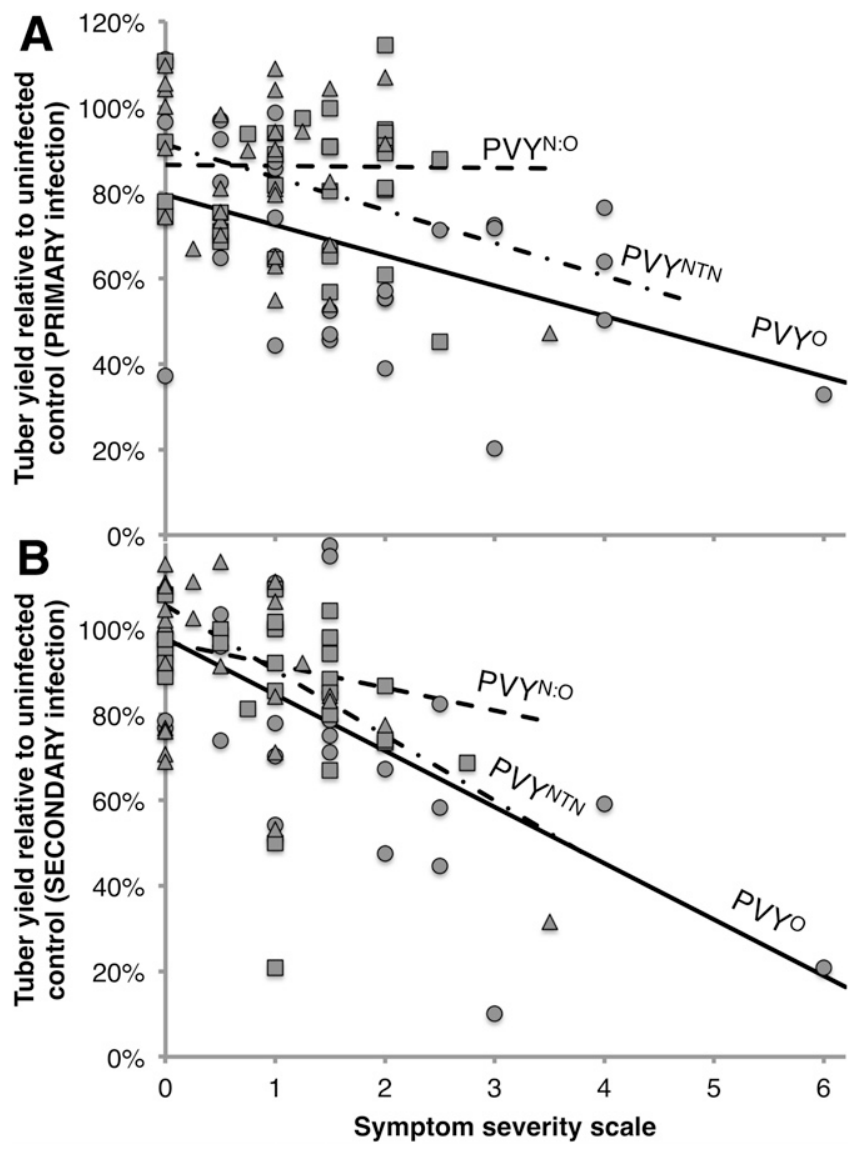

Fig. 4. Tuber yield versus foliar symptom severity in A, primary infection and B, secondary (seed tuberborne) infection. Each point represents an individual potato variety, infected with Potato virus $Y(P V Y)^{\mathrm{O}}$ (circles), PVY ${ }^{\mathrm{N}: \mathrm{O}}$ (squares), and PVYNTN (triangles). Trend lines represent least-squares regression lines for each strain, as indicated. 
Snowden also showed significant leaf deformation and drop, though little mosaic, and also retained good yield. Other varieties that showed good visible symptoms but retained high yield with $\mathrm{PVY} \mathrm{Y}^{\mathrm{N}: \mathrm{O}}$ and PVY ${ }^{\text {NTN }}$ included Chieftain, Monticello, and Norland, though Norland yield was severely affected by PVY ${ }^{\mathrm{O}}$. Conversely, several varieties which showed few or weak visible symptoms but suffered high yield loss represent a difficult situation for growers to manage. Examples of these are Beljade, Classic Russet, Innovator, Shepody, and Tenace. Similarly, some varieties do not show the characteristic mosaic symptom yet have high yield loss on infection, including Classic Russet and Clearwater Russet across strains, and Dakota Pearl, Ranger Russet, and Yukon Gold specifically with PVYNTN infection; also, Yukon Gold proved very susceptible to PTNRD with PVY ${ }^{\text {NTN }}$ infection.

\section{Discussion}

PVY strains cooccur and their population balance is dynamically shifting in potato crops around the world. The symptoms expressed following infection with these strains, and their effects on yield in different potato varieties, make a comprehensive study of specific strain-variety symptom expression and any cross-variety symptom generalities useful for management decision making, variety selection, disease eradication, and yield prediction.

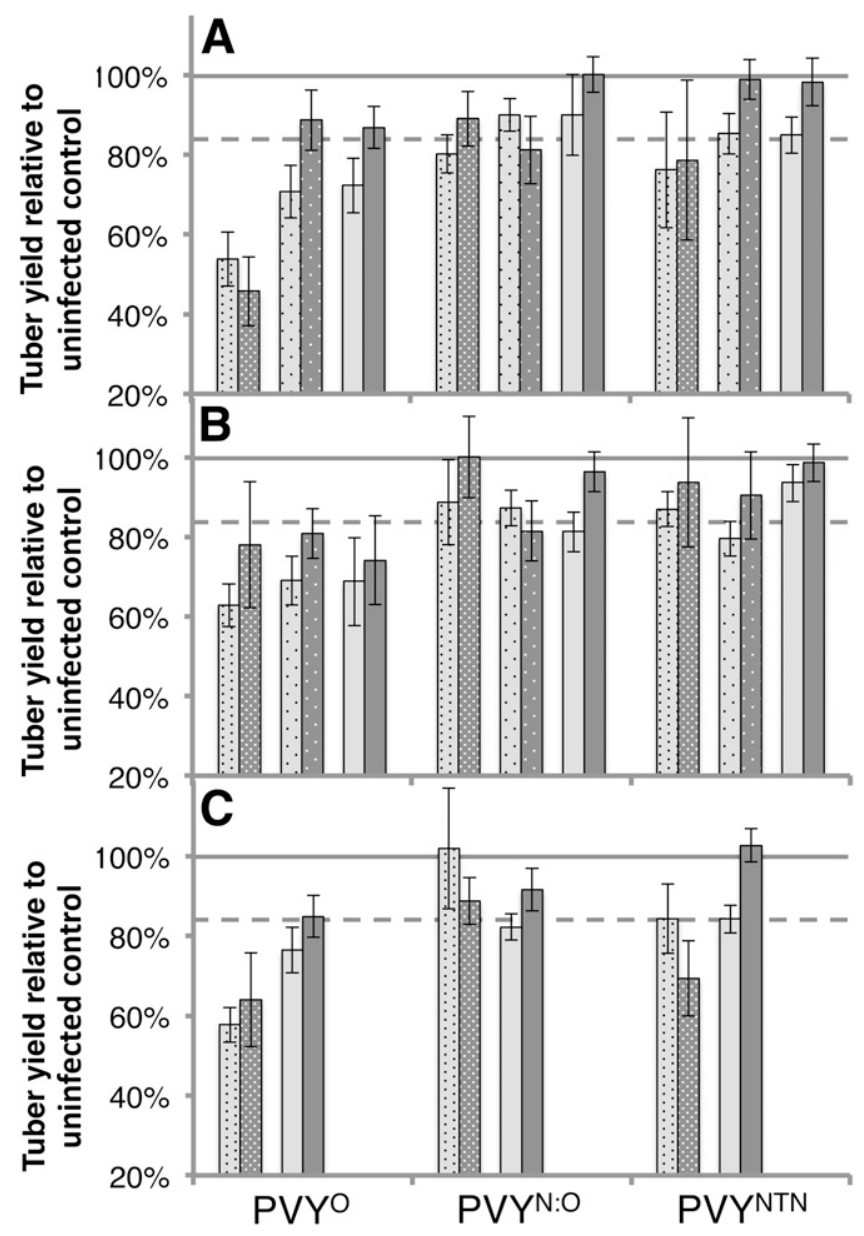

Fig. 5. Tuber yield loss as a function of Potato virus $Y$ (PVY) strain, type of infection, and foliar symptoms. Panels show yield loss in plants displaying A, mosaic; B, deformed leaves; or C, leaf drop, plant stunting, or early senescence. Pairs of columns show yield effect of strong symptom expression (heavy stipple), slight symptom expression (light stipple), or infected plants not showing the symptom (no stipple); in C, only presence (heavy stipple) or absence of the symptom (no stipple) is shown. In each pair of columns, light gray indicates primary infection and dark gray indicates secondary (tuberborne) infection; values are means of all varieties displaying the symptom \pm standard error of the mean. The solid horizontal background line in each panel indicates $100 \%$ yield of uninfected control plants and the dashed horizontal line at $84 \%$ represents average yield of all PVY-infected plants regardless of strain or variety.
Since their emergence two to three decades ago, many reports have been published around the world describing the rapid spread of recombinant $\mathrm{PVY}$ strains, replacing $\mathrm{PVY}^{\mathrm{O}}$ and other traditionally dominant nonrecombinants. These include potato production regions in Europe (Kamangar et al. 2014; Schubert et al. 2007), Asia (Bai et al. 2019; Chikh Ali et al. 2010; Djilani-Khouadja et al. 2010), and South America (Galvino-Costa et al. 2012). Until recently, $\mathrm{PVY}^{\mathrm{O}}$ has maintained a relatively high proportion of the PVY population in the United States and Canada (Gray et al. 2010; Nanayakkara et al. 2012). In a wide-ranging survey of North American isolates in 2004 to 2006, samples from 19 U.S. states showed $61 \%$ PVYO, $24 \%$ $\mathrm{PVY}^{\mathrm{N}-\mathrm{Wi}}$, and $5 \% \mathrm{PVY}^{\mathrm{NTN}}$ (10\% other or mixed infection), and 9 Canadian provinces showed $67 \% \mathrm{PVY}^{\mathrm{O}}, 27 \% \mathrm{PVY}^{\mathrm{N}-\mathrm{Wi}}$, and only $1.3 \% \mathrm{PVY}^{\mathrm{NTN}}$ (approximately $5 \%$ other or mixed infection) (Gray et al. 2010). However, these $\mathrm{PVY}^{\mathrm{O}}$-dominated populations have begun to shift toward dominance by recombinant PVY strains in more recent years (Funke et al. 2017). Also, our research group had followed PVY strain populations in a smaller survey between 2010 and 2016, though restricted to fewer samples sourced only from New Brunswick. Nevertheless, this earlier survey showed a shift from a $\mathrm{PVY}^{\mathrm{O}}$ - to $\mathrm{PVY}^{\mathrm{NTN}}$-dominated population, similar to the results of the broader present study (MacKenzie et al. 2018).

This study presents a 4-year survey of PVY strains in two major potato-producing regions in western and eastern Canada, both showing dramatic changes in dominant PVY strains. In these regions, $\mathrm{PVY}^{\mathrm{O}}$ has dropped by factors of 4 and 6 , respectively, replaced mostly by PVY ${ }^{\mathrm{N}-\mathrm{Wi}}$ and $\mathrm{PVY} \mathrm{Y}^{\mathrm{NTN}}$. This has also occurred, beginning a few years earlier, in the northwestern United States, adjacent to our western Canadian potato production region (Benedict et al. 2015). The population proportion of $\mathrm{PVY}^{\mathrm{O}}$ represented approximately half of all PVY in Washington and Oregon in 2011 but, by 2015, dropped 10-fold and 5-fold respectively, largely being replaced by $\mathrm{PVY}^{\mathrm{N}: \mathrm{O} / \mathrm{N}-\mathrm{Wi}}$ (specifically PVY ${ }^{\mathrm{N}-W i}$ in Washington) (Funke et al. 2017).

The novel recombinant PVY strains $\mathrm{PVY}^{\mathrm{N}: \mathrm{O}}, \mathrm{PVY}^{\mathrm{N}-\mathrm{Wi}}$, and $\mathrm{PVY}^{\mathrm{NTN}}$ quickly replacing $\mathrm{PVY} \mathrm{O}^{\mathrm{O}}$ around the world represent several new challenges to producers. First, several of these strains, especially PVY ${ }^{\mathrm{NTN}}$, spread between plants more quickly than other strains by aphids or mechanical sap transmission in the field (Funke et al. 2017; MacKenzie et al. 2018). Second, recombinant PVY strains typically show more cryptic symptoms, hampering detection and eradication in the field. Third, the increasingly common PVYNTN strain can cause tuber necrosis (PTNRD) in susceptible varieties, which can result in unmarketability of an entire crop.

Several groups have recently highlighted the wide range of visible symptoms from infection with different PVY strains in different potato varieties (Lindner et al. 2015; Nie et al. 2012; Rowley et al. 2015). Traditionally, visual examination by potato growers and extension personnel has been used to assess and manage levels of PVY in the field. However, with more cryptic symptoms associated with the rising populations of recombinant PVY strains, this approach may be problematic. Only approximately two-thirds of varieties in this study showed any degree of the most recognized mosaic symptom with PVY infection, and it was generally weakly expressed in most strain-variety combinations; clear and strong mosaic symptoms were mostly seen with the increasingly uncommon $\mathrm{PVY}^{\mathrm{O}}$ strain. Mosaic, however, may be stronger in more varieties under field conditions, with multiple other biotic and abiotic stresses exacerbating it. In the greenhouse, more varieties showed leaflet deformation than mosaic, and showed it more consistently across strains. Also, a smaller number, particularly with $\mathrm{PVY}^{\mathrm{O}}$, displayed early senescence and leaf drop. These latter symptoms are not unique to PVY infection, though, and could easily be mistaken in the field for drought stress, waterlogging, nutrient deficiency, insect damage, or symptoms of another disease agent.

Tuber yield across variety-strain combinations varied widely, from no significant yield reduction up to $90 \%$ reduction compared with control (noninfected) plants. In a series of field trials in 1996 and 1997 in Oregon and northern California in the United States, Rykbost et al. (1999) showed yield reductions of 0.15 to $0.52 \%$ per 1\% PVY incidence in fields of Russet Norkotah, or ranging 
between 15 and $52 \%$ per infected plant across the fields and crop seasons. Although highly variable in this variety from year to year, yield reduction was strongly correlated with PVY within a given region and crop year, suggesting that PVY-induced yield reduction is also affected by local environmental conditions. Given the location and time of these trials, Rykbost et al. (1999) were probably dealing almost exclusively with $\mathrm{PVY}{ }^{\mathrm{O}}$, which we found to be far more damaging to yield than other strains. Indeed, our study showed stark differences between the strains on tuber yield. Taking $10 \%$ tuber yield reduction as an arbitrary threshold for practically significant yield loss, only five and seven varieties showed less than that in primary and secondary $\mathrm{PVY} \mathrm{Y}^{\mathrm{O}}$ infection, respectively. However, in primary and secondary infection with $\mathrm{PVY}^{\mathrm{N}: \mathrm{O}}, 11$ and 14 varieties remained at less than $10 \%$ yield loss and, in $\mathrm{PVY}^{\mathrm{NTN}}, 11$ and 17 varieties. Given the gentle conditions of the greenhouse, replete with water and nutrition and no aggravating factors such as coinfections with other pathogens or pest predation, these loss estimates are likely very conservative (Choi et al. 2017; Nie and Singh 2013). A further caveat is that PVY infection of all these varieties, while replicated, were each experimented upon over a single growth window. Seasonal changes in the greenhouse may also affect symptom expression although, in our study, all measured quantities and symptoms were directly compared with control plants of the same variety at the same time in the greenhouse. Ideally, these series of experiments would be replicated either in the greenhouse or, better, in the field to validate the conclusions we have drawn in this study.

The wide ranges of foliar symptom severity and yield reduction across PVY strains and varieties prompts questions over whether yield reduction is caused by disease damage to the foliage, and whether visible symptom expression aboveground is useful for predicting tuber yield belowground. We observed that aggregate symptom severity, as measured by "symptom severity scale", was correlated with lowered tuber yield when looking at all varieties and strains. However, most of this effect was due to the relatively severe reactions of many varieties to $\mathrm{PVYO}$ infection and, when correlations were grouped by strain, only $\mathrm{PVY}^{\mathrm{O}}$ remained highly significant.

It is debatable whether foliar damage from these symptoms directly caused the lower yield or whether PVY caused yield reduction independent of foliar symptoms. Specifically, the foliar symptoms best correlated with yield reduction were mosaic and, though relatively less frequent, leaf drop and early plant senescence. Nie et al. (2012) also reported varying responses of varieties to infection by different PVY strains, and noted that variety-strain combinations that showed the strongest foliar symptoms were also associated with greater yield reductions. Presumably, decline of photosynthetic productivity due to leaf damage, and productive lifetime with early senescence, could reduce photosynthate investment in the tubers. However, here, the symptom severity only correlated well with yield for $\mathrm{PVY}^{\mathrm{O}}$ infections. The presence of similar symptoms with other strains did not correspond to statistically significant reductions in yield. Also, more common leaf deformation symptoms did not significantly correspond to differences in tuber yield with any strain. Presumably, these symptoms themselves would have some impact on the photosynthetic capacity of the plant, regardless of PVY strain; however, perhaps less visible effects of infection are more influential on tuber yield. With poor correlation of symptom severity in general or the correspondence of particular symptoms with tuber yield, using symptom expression predictively would not be universally applicable across potato varieties. Also, with the rise of recombinant PVY strains across most potato-producing regions of the world, the particularly poor correlation of symptom severity and yield with infections by these strains further limits this predictability.

In the commercial setting, growers are unlikely to test for PVY incidence or strain composition in the growing crop before harvest, instead relying on visual identification for roguing infected plants from the field. With the newly prominent recombinant PVY strains, however, only a narrow range of particular varieties exist in which symptoms are strong and easily recognizable but in which yield loss is relatively low. Atlantic and Snowden specifically were identified as potential indicator plants, showing strong foliar symptoms with any PVY strain yet maintaining high yield despite infection. Several others, including Chieftain, Monticello, and Norland, showed similar promise specifically with PVY ${ }^{\mathrm{N}: \mathrm{O}}$ and PVY ${ }^{\mathrm{NTN}}$. Alternatively, several varieties were identified with cryptic foliar symptoms yet suffering relatively high yield reduction. These included Beljade, Classic Russet, Innovator, Shepody, Tenace, Classic Russet, and Clearwater Russet across strains, and Dakota Pearl, Ranger Russet, and the PTNRD-susceptible Yukon Gold specifically with PVY ${ }^{\text {NTN }}$ infection. Knowing the predominant strains in a region and their symptom response and yield effects could be very beneficial for growers' decision making regarding varieties to plant.

Of 30 tested varieties in this study, only 4 displayed PTNRD, the most concerning consequence of PVY ${ }^{\mathrm{NTN}}$ infection. In a previous study of variety-strain responses, Nie et al. (2012) also found few varieties ( 2 of 14 tested) showing PTNRD but noted a correspondence between PTNRD and foliar symptom severity with PVY ${ }^{\text {NTN }}$ infection. In this study, however, of the four varieties with PTNRD - AC Chaleur, Envol, Yukon Gold, and Pacific Russet-the latter two showed relatively weaker symptoms compared with non-PTNRD varieties infected with PVY ${ }^{\mathrm{NTN}}$, and none of the four showed significant mosaic symptoms. Averaged across the four, however, symptom severity scores were double and triple the average of non-PTNRD varieties in primary and secondary infection, respectively. Nie et al. (2012) also showed that many varieties showed intense foliar symptoms from the "severe" $\mathrm{PVY} \mathrm{O}^{\mathrm{O}} \mathrm{FL}$ isolate, yet none displayed PTNRD, which we confirmed in this study.

Beyond the likely consequence of unmarketability of a PTNRDaffected crop, those varieties susceptible to it also showed much reduced yield. PVY ${ }^{\mathrm{NTN}}$ infection reduced yield by $30 \%$ in PTNRDsusceptible varieties but only by $7 \%$ in non-PTNRD-susceptible ones. Also, in these particular varieties, yield loss was nearly twice as severe from infection by other strains than by non-PTNRD varieties (27 versus $15 \%$ ). Thus, due to extraordinary yield loss and potential for PTNRD, it may be prudent to avoid production of these varieties if PVY pressure is high, regardless of the PVY strains in a region but especially if PVY ${ }^{\mathrm{NTN}}$ is predominant.

In conclusion, this study has shown that, in recent years, a significant shift of PVY strains occurred in Canada toward relatively recently emerged recombinant strains, and that plant responses to infection with these strains vary widely between varieties and are different than traditional PVY ${ }^{\mathrm{O}}$ symptoms. This study highlights the importance of local monitoring of predominant PVY strains, and more widespread knowledge among potato producers about the varietyspecific responses to particular PVY strains. The present study showed intriguing trends for foliar symptom expression and yield reduction in these greenhouse-grown plants, as well as several varieties susceptible to PTNRD. In future, comparing these variety-strain responses in field-grown plants of the same varieties would be an important next step to validate these findings. Along with the comprehensive cataloguing of symptom responses to PVY strains completed in this study, several potato varieties were identified showing either strong foliar symptoms with low impact on tuber yield or quality or others with cryptic symptoms but large reductions in tuber yield. The results of this study provide useful information not only for researchers studying PVY strains, but practically important information to potato producers to help inform decision making about variety choice, given the shifting strain composition of PVY populations in Canada and around the world.

\section{Acknowledgments}

We thank T. Shinners-Carnelly, M. Sonier, the BC Potato and Vegetable Growers Association, Fédération des producteurs de pommes de terre du Québec, PEI Potato Board, PotatoesNB, Potato Growers of Alberta, and the Seed Potato Growers Association of Manitoba for making valued contributions to this study; and numerous individual potato producers for submitting samples for our national PVY survey.

\section{Literature Cited}

Bai, Y., Han, S., Gao, Y., Zhang, W., Fan, G., Qiu, C., Nie, X., and Wen, J. 2019. Genetic diversity of Potato virus $Y$ (PVY) in potato production areas in northeast China. Plant Dis. 103:289-297. 
Beczner, L., Horvath, J., Romhanyi, I., and Forster, H. 1984. Studies on the etiology of tuber necrotic ringspot disease in potato. Potato Res. 27:339-352.

Benedict, C. A., McMoran, D. W., Inglis, D. A., and Karasev, A. V. 2015. Tuber symptoms associated with recombinant strains of Potato virus $Y$ in specialty potatoes under western Washington growing conditions. Am. J. Potato Res. 92:593-602.

Blanchard, A., Rolland, M., Lacroix, C., Kerlan, C., and Jacquot, E. 2008. Potato virus $Y$ : A century of evolution. Curr. Top. Virol. 7:21-32.

Chikh-Ali, M., Gray, S. M., and Karasev, A. V. 2013. An improved multiplex IC-RT-PCR assay distinguishes nine strains of Potato virus Y. Plant Dis. 97: 1370-1374.

Chikh Ali, M., Maoka, T., Natsuaki, K. T., and Natsuaki, T. 2010. The simultaneous differentiation of Potato virus $Y$ strains including the newly described strain PVY ${ }^{\text {NTN-NW }}$ by multiplex PCR assay. J. Virol. Methods 165:15-20.

Choi, K. S., del Toro, F., Tenllado, F., Canto, T., and Chung, B. N. 2017. A model to explain temperature dependent systemic infection of potato plants by Potato virus Y. Plant Pathol. J. 33:206-211.

Cockerham, G. 1943. The reactions of potato varieties to viruses X, A, B and C. Ann. Appl. Biol. 30:338-344.

Davie, K., Holmes, R., Pickup, J., and Lacomme, C. 2017. Dynamics of PVY strains in field grown potato: Impact of strain competition and ability to overcome host resistance mechanisms. Virus Res. 241:95-104.

Djilani-Khouadja, L., Glais, M., Kerlan, C., Tribodet, M., and Fakhfakh, H. 2010. Incidence of potato viruses and characterisation of Potato virus $Y$ variability in late season planted potato crops in northern Tunisia. Eur. J. Plant Pathol. 126:479-488.

Draper, M. D., Pasche, J. S., and Gudmestad, N. C. 2002. Factors influencing PVY development and disease expression in three potato cultivars. Am. J. Potato Res. 79:155-165.

Funke, C. N., Nikolaeva, O. V., Green, K. J., Tran, L. T., Chikh-Ali, M., QuinteroFerrer, A., Cating, R. A., Frost, K. E., Hamm, P. B., Olsen, N., Pavek, M. J., Gray, S. M., Crosslin, J. M., and Karasev, A. V. 2017. Strain-specific resistance to Potato virus $Y$ (PVY) in potato and its effect on the relative abundance of PVY strains in commercial potato fields. Plant Dis. 101:20-28.

Galvino-Costa, S. B., dos Reis Figueira, A., de Assis Câmara Rabelo-Filho, F., Moraes, F. H. R., Nikolaeva, O. V., and Karasev, A. V. 2012. Molecular and serological typing of Potato virus $Y$ isolates from Brazil reveals a diverse set of recombinant strains. Plant Dis. 96:1451-1458.

Gray, S., De Boer, S., Lorenzen, J., Karasev, A., Whitworth, J., Nolte, P., Singh, R. P., Boucher, A., and Xu, H. 2010. Potato virus Y: An evolving concern for potato crops in the United States and Canada. Plant Dis. 94:1384-1397.

Green, K. J., Brown, C. J., Gray, S. M., and Karasev, A. V. 2017. Phylogenetic study of recombinant strains of Potato virus $Y$. Virology 507:40-52.

Gugerli, P., and Gehriger, W. 1980. Enzyme-linked immunosorbent assay (ELISA) for the detection of potato leafroll virus and Potato Virus $Y$ in potato tubers after artificial break of dormancy. Potato Res. 23:353-359.

Jones, R. A., and Vincent, S. J. 2018. Strain-specific hypersensitive and extreme resistance phenotypes elicited by Potato virus $Y$ among 39 potato cultivars released in three world regions over a 117-year period. Plant Dis. 102:185-196.

Kamangar, S. B., Smagghe, G., Maes, M., and De Jonghe, K. 2014. Potato virus $Y$ (PVY) strains in Belgian seed potatoes and first molecular detection of the N-Wi strain. J. Plant Dis. Prot. 121:10-19.

Karasev, A. V., and Gray, S. M. 2013. Continuous and emerging challenges of Potato virus $Y$ in potato. Annu. Rev. Phytopathol. 51:571-586.

Kehoe, M. A., and Jones, R. A. C. 2015. Improving Potato virus $Y$ strain nomenclature: Lessons from comparing isolates obtained over a 73-year period. Plant Pathol. 65:322-333.
Lindner, K., Trautwein, F., Kellermann, A., and Bauch, G. 2015. Potato virus $Y$ (PVY) in seed potato certification. J. Plant Dis. Prot. 122:109-119.

Lorenzen, J. H., Piche, L. M., Gudmestad, N. C., Meacham, T., and Shiel, P. 2006 A multiplex PCR assay to characterize Potato virus $Y$ isolates and identify strain mixtures. Plant Dis. 90:935-940.

MacKenzie, T. D. B., Lavoie, J., Nie, X., and Singh, M. 2018. Differential spread of Potato virus $Y$ (PVY) strains $\mathrm{O}, \mathrm{N}: \mathrm{O}$ and $\mathrm{NTN}$ in the field: Implications for the rise of novel PVY strains in New Brunswick, Canada. Am. J. Potato Res. 95:301-310.

Nanayakkara, U. N., Singh, M., Pelletier, Y., and Nie, X. 2012. Investigation of Potato virus $Y$ strain status and variant population in potatoes in New Brunswick, Canada. Am. J. Potato Res. 89:232-239.

Nie, B., Singh, M., Murphy, A., Sullivan, A., Xie, C., and Nie, X. 2012. Response of potato cultivars to five isolates belonging to four strains of Potato virus Y. Plant Dis. 96:1422-1429.

Nie, B., Singh, M., Sullivan, A., Singh, R. P., Xie, C., and Nie, X. 2011. Recognition and molecular discrimination of severe and mild PVYO variants of Potato virus $Y$ in potatoes in New Brunswick, Canada. Plant Dis. 95:113-119.

Nie, X., Liang, Z., Nie, B., Murphy, A., and Singh, M. 2015. Studies on varietal response to different strains of Potato virus $Y$ (PVY) reveal hypersensitive resistance in Exploits to PVY ${ }^{\mathrm{O}}$ and extreme resistance in F87084 to all tested strains. Am. J. Potato Res. 92:23-31.

Nie, X., and Singh, M. 2013. Response of potato, tobacco and Physalis floridana plants to mixed infection with PVX, PVY ${ }^{\mathrm{NTN}}$ and PVY ${ }^{\mathrm{O}}$ strains. Can. J. Plant Pathol. 35:390-401

Nie, X., and Singh, R. P. 2001. A novel usage of random primers for multiplex RT-PCR detection of virus and viroid in aphids, leaves, and tubers. J. Virol Meth. 91:37-49.

Nie, X., Singh, R. P. and Singh, M. 2004. Molecular and pathological characterization of $\mathrm{N}: \mathrm{O}$ isolates of the Potato virus $Y$ from Manitoba, Canada. Can. J. Plant Pathol. 26:573-583.

Rowley, J. S., Gray, S. M., and Karasev, A. V. 2015. Screening potato cultivars for new sources of resistance to Potato virus $Y$. Am. J. Potato Res. 92:38-48.

Rykbost, K. A., Hane, D. C., Hamm, P. B., Voss, R., and Kirby, D. 1999. Effects of seedborne potato virus $Y$ on Russet Norkotah performance. Am. J. Potato Res 76:91-96.

Schubert, J., Fomitcheva, V., and Sztangret-Wiśniewska, J. 2007. Differentiation of Potato virus $Y$ strains using improved sets of diagnostic PCR-primers. J. Virol. Methods 140:66-74.

Singh, R. P., McLaren, D. L., Nie, X., and Singh, M. 2003. Possible escape of a recombinant isolate of Potato virus $Y$ by serological indexing and methods of its detection. Plant Dis. 87:679-685.

Singh, R. P., Valkonen, J. P. T., Gray, S. M., Boonham, N., Jones, R. A. C., Kerlan, C., and Schubert, J. 2008. Discussion paper: The naming of Potato virus $Y$ strains infecting potato. Arch. Virol. 153:1-13.

Valkonen, J. P. T., Gebhardt, C., Zimnoch-Guzowska, E., and Watanabe, K. N 2017. Resistance to Potato virus $Y$ in potato. Pages 207-241 in: Potato virus $Y$ : Biodiversity, Pathogenicity, Epidemiology and Management. C. Lacomme, L. Glais, D. Bellstedt, B. Dupuis, A. Karasev, and E. Jacquot, eds. Springer, Cham, Switzerland.

van Eck, H. J., Vos, P. G., Valkonen, J. P., Uitdewilligen, J. G., Lensing, H., de Vetten, N., and Visser, R. G. 2017. Graphical genotyping as a method to map $\mathrm{Ny}(\mathrm{o}, \mathrm{n})$ sto and Gpa5 using a reference panel of tetraploid potato cultivars. Theor. Appl. Genet. 130:515-528.

Visser, J. C., Bellstedt, D. U., and Pirie, M. D. 2012. The recent recombinan evolution of a major crop pathogen, Potato virus $Y$. PLOS One 7:e50631. 